NBER WORKING PAPER SERIES

THE PERSISTENCE OF VOLATILITY AND

STOCK MARKET FLUCTUATIONS

James M. Poterba

Lawrence H. Summers

Working Paper No. 1462

NATIONAL BUREAU OF ECONOMIC RESEARCH

1050 Massachusetts Avenue

Cambridge, MA 02138

September 1984

We are indebted to Carla Ponn and especially to Ignacio Mas for research assistance, to Fischer Black and Robert Merton for helpful discussions, and to the NBER and the NSF for financial support. The research reported here is part of the NBER's research program in Financial Markets and Monetary Economics. Any opinions expressed are those of the authors and not those of the National Bureau of Economic Research. 


\title{
The Persistence of Volatility and \\ Stock Market Fluctuations
}

\begin{abstract}
This paper examines the potential influence of changing volatility in stock market prices on the level of stock market prices. It demonstrates that volatility is only weakly serially correlated, implying that shocks to volatility do not persist. These shocks can therefore have only a small impact on stock market prices, since changes in volatility affect expected required rates of return for relatively short intervals. These findings lead us to be skeptical of recent claims that the stock market's poor performance during the 1970's can be explained by volatility-induced increases in risk premia.
\end{abstract}

James M. Poterba Department of Economics Massachusetts Institute of Technology Cambridge, MA 02139 (617) 253-6673
Lawrence H. Summers Department of Economics Harvard University Cambridge, MA 02138 (617) 495-2447 
This paper examlnes the potential influence of changing stock market volatility on the level of stock market prices. It demonstrates that volatility is only weakly serially correlated, Implying that shocks to volatility do not persist. These shocks can therefore have only a small impact on stock market prices, since changes in volatility affect expected required rates of return for only short intervals. These findings lead us to be skeptical of recent claims that the stock market's poor performance during the $1970^{\prime} \mathrm{s}$ can be explained by volatility-induced increases in risk premia, as suggested by Malkiel (1979) and Pindyck (1984). They also lead us to doubt that fluctuations in risk premia associated with changing return volatility can account for mach of the observed variation in stock prices. The finding that volatility is not highly serially correlated is puzzling in light of Black's (1976) observation that stock market returns and changes in volatility are negatively correlated.

The paper is divided into five sections. The first clarifies the theoretical relationship between return volatility, the level of share prices, and required rates of return. The second section examines the time series properties of stock market volatility as measured using both monthly and daily data. The results suggest that although volatility is serially correlated, changes in current volatility should have only a negligible impact on volatility forecasts over intervals as short as one or two years. The third and fourth sections use data on the implied volatilities in option premia to re-examine the persistence question, and again find evidence of only weak serial correlation. The conclusion discusses the implications of our results for alternative explanations of recent stock market movements and for our understanding of the sources of asset price fluctuations more generally. 


\section{Volatility, Required Returns, and Stock Price Fluctuations}

This section discusses the relationship between changes in volatility and changes in the level of stock market prices. For simplicity we assume that firms are not levered and that expected dividends grow at a constant rate. The former assumption allows us to ignore Black's (1976) important observation that the level of share prices, by affecting the degree of leverage, should have a direct impact on volatility. The latter assumption is maintained for convenience and could be relaxed easily. Because of the nature of the volatility estimates used in our empirical work, we use a discrete time formulation.

We assume that share prices satisfy the standard requirement that

$$
\frac{E_{t}\left(P_{t+1}\right)-P_{t}}{P_{t}}+\frac{D_{t}}{P_{t}}=r_{t}+a_{t}
$$

where $r_{t}$ is the risk-free interest rate, $\alpha_{t}$ is the risk premium, and $D_{t}$ is the dividend paid in period t. Equivalently, equation (1) can be written as :

$$
P_{t+1}=\left(1+r_{t}+\alpha_{t}\right) P_{t}-D_{t}+\varepsilon_{t} P_{t}
$$

where

$$
\varepsilon_{t}=\left(P_{t+1}-E_{t}\left[P_{t+1}\right]\right) / P_{t}
$$

is a random disturbance assumed to be uncorrelated with any information available at time t. It reflects the impact of revisions in expectations about future values of $D, \alpha$, and $r$ which take place between periods $t$ and $t+1$.

Equation (2) is a difference equation for $P_{t}$, and it can be solved rorward subject to an appropriate transversality condition to yield

$$
P_{t}=E_{t}\left[\sum_{j=0}^{\infty}\left\{\prod_{i=0}^{j}\left(1+\alpha_{t+1}+r_{t+1}\right)^{-1}\right\} D_{t+j}\right] .
$$


Assuming that the risk free rate is constant over time, this expression may be IInearized around the mean value of $\alpha, \bar{\alpha}$, to obtain:

$$
\left.P_{t}=\sum_{j=0}^{\infty} \frac{E_{t}\left[D_{t+j}\right]}{(1+r+\bar{\alpha})^{j}}+\sum_{j=0}^{\infty} \frac{d P_{t}}{d \alpha_{t+j}}\left(E_{t} \mid \alpha_{t+j}\right]-\bar{\alpha}\right)
$$

where

$$
\frac{d P_{t}}{d \alpha_{t+j}}=-(1+r+\bar{\alpha})^{-J-1} \cdot \sum_{k=0}^{\infty} \frac{E_{t}\left(D_{t+j+k}\right)}{(1+r+\bar{\alpha})^{k}} \text {. }
$$

Equation (5) expresses current stock prices as a linear function of expected future risk premia. Assuming that expected dividends grow at a constant rate $B$, so that $E_{t}\left[D_{t+j}\right]=(1+g)^{j} D_{t}$, the derivative in $(6)$ can be simplified as:

$$
\frac{d P_{t}}{d \alpha_{t+j}}=\frac{-D_{t}(1+g)^{J}}{(1+r+\bar{\alpha})^{j+1}} \sum_{k=0}^{\infty} \frac{(1+g)^{k}}{(1+r+\bar{\alpha})^{k}}=\frac{-D_{t}(1+g)^{J}}{(1+r+\bar{\alpha})^{j}(r+\bar{\alpha}-g)} .
$$

It is natural to postulate that $\alpha_{t}$ depends on $\sigma_{t}^{2}$, the variance of $\varepsilon_{t}$. We assume for simplicity that

$$
\alpha_{t}=r \sigma_{t}^{2}
$$

where $\gamma$ is a constant of proportionality that depends on investors' levels of risk aversion. Merton $(1973,1980)$ derives a similar relationship between $\alpha_{t}$ and the variance of returns in a continuous-time model.

To study the effect of changes in volatility on $\mathrm{P}_{t}$ it is necessary to adopt some assumption about the evolution of $\sigma_{t}^{2}$. We assume that $\sigma_{t}^{2}$ follows an $\operatorname{AR}(1)$ process:

$$
\sigma_{t}^{2}=\rho_{0}+\rho_{1} \sigma_{t-1}^{2}+\mu_{t}
$$

Evidence to support the $A R(1)$ assumption is presented in subsecuent sections. 
From (8) and (9), 1t 1mmediately follows that $\alpha_{t}$ also follows an AR(1) process:

$$
a_{t}=r p_{0}+p_{1} a_{t-1}+v_{t}
$$

where $\nu_{t}=\gamma \mu_{t}$. The mean value of $\alpha_{t}$ 1s therefore $\gamma p_{0} /\left(1-p_{1}\right)$, and the deviatIon between $\alpha_{t}$ and $\bar{\alpha}$ obeys

$$
\alpha_{t}-\bar{\alpha}=p_{1}\left(\alpha_{t-1}-\bar{\alpha}\right)+\nu_{t}
$$

Equation (11) enables us to simplify (5) substantially, since $E_{t}\left(\alpha_{t+j}-\bar{\alpha}\right)=$ $\rho_{1}^{j}\left(\alpha_{t}-\bar{\alpha}\right)$. Substituting this relationship into (5) and using (7) yields

$$
\begin{aligned}
P_{t} & =\sum_{j=0}^{\infty} \frac{E_{t}\left(D_{t+j}\right)}{(1+r+\bar{\alpha})^{j}}-\sum_{j=0}^{\infty} \frac{D_{t}(1+g)^{j} \rho_{1}^{j}\left(\alpha_{t}-\bar{\alpha}\right)}{(1+r+\bar{\alpha})^{j}(r+\bar{\alpha}-g)} \\
& =\frac{D_{t}(1+r+\bar{\alpha})}{r+\bar{\alpha}-g}-\left[\frac{1+r+\bar{\alpha}}{1+r+\bar{\alpha}-\rho_{1}(1+g)}\right] \cdot\left[\frac{D_{t}}{r+\bar{\alpha}-g}\right]\left(\alpha_{t}-\bar{\alpha}\right)
\end{aligned}
$$

The last expression shows the effect of risk premia shocks on share prices; the second term is $\left(d P_{t} / d \alpha_{t}\right) \cdot\left(\alpha_{t}-\bar{\alpha}\right)$. This may be rewritten in terms of volatility shocks, using ( 8$)$, as

$$
\frac{d P_{t}}{d \sigma_{t}^{2}}=\frac{-r(1+r+\bar{\alpha})}{\left[1+r+\bar{\alpha}-\rho_{1}(1+g)\right]} \cdot\left[\frac{D_{t}}{r+\bar{\alpha}-g}\right]
$$

or

$$
\frac{d \log P_{t}}{d \log \sigma_{t}^{2}}=\frac{-\gamma \sigma_{t}^{2} \lambda_{t}}{\left[1+r+\bar{\alpha}-\rho_{1}(1+g)\right]} \cdot \frac{[1+r+\bar{\alpha}]}{[r+\bar{\alpha}-g]}
$$

where $\lambda_{t}$ is the dividend yield, $D_{t} / P_{t}$. The numerator simplifies since $r \sigma^{2}=\alpha_{t}$ and $\lambda_{t}=r_{t}+\alpha_{t}-g$. Evaluating both expressions at $\bar{\alpha}$ yields 


$$
\frac{d \log _{t} P_{t}}{d \log \sigma_{t}^{2}}=\frac{-\bar{\alpha}[1+r+\bar{a}]}{\left[1+r+\bar{\alpha}-\rho_{1}(1+B)\right]}
$$

Notice that the absolute value of the derivative of share prices with respect to current volatility rises with $p_{1}$. This result is intuitively natural. If increases in volatility are expected to persist, they will have a greater Impact on the discount factors applied to future cash flows, and therefore on share prices.

In order to examine possible relationships between volatility and the level of share prices, it is useful to insert some plausible parameter values into (15). The mean annual return on common stocks for the period 1948-1983 was 11.6 percent.l The mean nominal return on Treasury bills was 4.6 percent per year over the same period, implying an average value of 7.0 percent for $a$. The average real return on Treasury bills, which we use to estimate r, was .4 percent. The estimated variance of the market return, expressed at annual rates, ranged from 26.83 in 1964 to 638.57 in 1974 , averaging 238.3 . The last statistic in confunction with the mean estimate for $\alpha$ implies a value of .029 for r. Merton (1980) estimated this parameter to be .032 for the period $1952-1978$. The growth rate of nominal dividends on the S\&P 500 during the 1948-1983 period was 5.2 percent annually. Combining this with our inflation rate of 4.2 percent yields an average growth rate for real dividends, $g$, of .01 .

The effect of changes in volatility on the level of share prices is very sensitive to the level of $P_{1}$. The derivative in (15) equals -.070 when $\rho_{1}=0$, .131 when $\rho_{1}=.5$, and -.409 when $\rho_{1}=.9$. We have defined $\rho_{1}$ as the serial corre- 
lation in annual volatility; an annual value or $P_{1}=.90$ implies a monthly autocorrelation of more than .99. Stated another way, a 50 percent increase in market volatility from its average level would reduce the value of the market by 3.5 percent if $P_{1}=0$, by 6.5 percent of $p_{1}=.5$, and by 20 percent if $p_{1}=.9$. It is clear that if fluctuations in volatility are to play a significant role in explaining market fluctuations, then $P_{1}$ must be quite large: The next two sections examine the serial correlation properties of several measures of volatiIity. 


\section{Serial Correlation in Market Volatility}

As emphasized in Merton (1980), a great deal of work remains to be done on variance estimation. In this section, we use crude estimators for the variance of market returns to study the serial correlation properties of volatility.2 We use two estimators of market variance, $\hat{\sigma}_{t}^{2}$ and $\hat{\sigma}_{t}^{2}$, computed respectively from monthly and daily returns data. While dally data are preferable for variance estimation, they were available to us only for the $1968-84$ period. Monthly returns data were avallable from 1926 to 1983.

\subsection{Volatility Estimation Using Monthly Data}

Our first variance estimator, based on monthly data, was calculated as:

$$
\tilde{\sigma}_{t}^{2}=\sum_{i=1}^{12}\left(s_{i t}-r_{i t}\right)^{2} / 12
$$

where $s_{i t}$ denotes the annualized return on common stocks in month 1 of year $t$, and $r_{i t}$ is the Treasury bill rate. 3 our monthly returns data were obtained from Ibbotson (1984).

In Table 1, we report summary statistics on $\hat{\sigma}_{t}^{2}$ for two periods, 1926-1983 and 1948-83. It is immediately clear from the autocorrelogram and partial autocorrelogram that there is no substantial positive serial correlation in market volatility. For the 1948-1983 period, the first order autocorrelation coefficient is only .114; for the longer $1926-83$ period, it is .675 . The high autocorrelation coefficlent for the whole period is sensitive to the inclusion of the Depression years in the data sample. The first order autocorrelation for the sample period $1935-1983$ is .50 , and for the 1940-1983 period, the estimate declines to .05 . Results similar to those for the postwar period were obtained 
Table 1: Autocorrelation in Annual Stock Market Volatilities

1926-1983 Sample 1948-1983 Sample

Lag Length (Years)

Partial

Autocorrelation Autocorrelation

Autocorrelation

Partial

Autocorrelation

1

$0.675(.131)$

$0.675(.131)$

$0.114(.167)$

$0.114(.167)$

2

$0.269(.131)$

$-0.345(.131)$

$-0.115(.167)$

$-0.129(.166)$

3

$0.110(.131)$

$0.206(.131)$

$-0.224(.167)$

$-0.200(.167)$

4

$0.077(.131)$

$-0.058(.131)$

$0.233(.166)$

$0.287(.167)$

5

$0.145(.131)$

$0.217(.131)$

$0.008(.160)$

$-0.122(.167)$

6

$0.215(.131)$

$0.002(.125)$
$0.255(.167)$

Source: Annual volatility estimates were calculated as the average of twelve squared monthly values of the return on common stocks minus the return Treasury bills. These data were drawn from Ibbotson (1984) for the period 1926-1983, a total of 696 observations. The second sample, for the 1948-1983 period, contains 432 observations. Standard errors are shown in parentheses. See text for further details. 
using data for only the 1960-1983 perlod, when the estimated first order serial correlation coefficient was .131. The hypothesis that annual volatility was a white noise process could be rejected at standard levels in the 1948-1983 or 1960-1984 periods. 4

As a further check on the autocorrelation properties of our volatility estimates, we estimated some simple autoregressive models for $\hat{o}_{t}^{2}$. The results, whlch are presented in Table 2, corroborate the conclusions reached above. They suggest no great persistence in volatility, and indicate that the simple first order autoregressive model used in the preceding section's theoretical development fits the data quite well.5 Higher order models did not yield appreciably smaller sums of squared residuals for either sample period under consideration.

The point estimates of $P_{1}$ for each sample period are substantially less than unity. They imply that volatility shocks do not persist for long periods. For the 1926-1983 sample perod, where we find the greatest amount of persistence, ninety percent of a volatility shock will have dissipated by six years after the shock. In the $A R(2)$ case for this period, only four years are required. The half life of the shock, the time required to move half way back to the long-run equilibrium, is two years for both processes. In the postwar period, the implied half life is much shorter -- less than one year.6 These results confirm Schmalensee and Trippi's (1978) findings of relatively little persistence in volatility for individual firms.

The estimated autocorrelations all suggest little persistence in volatility, and conventional t-tests reject the hypothesis that volatility is a random walk $\left(\rho_{1}=1\right)$. However, recent work on the estimation of time series models with unit roots, such as Dickey and Fuller (1981), has shown that the actual 
章

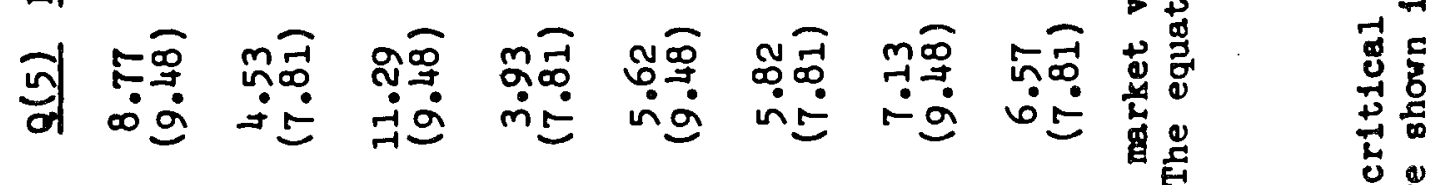

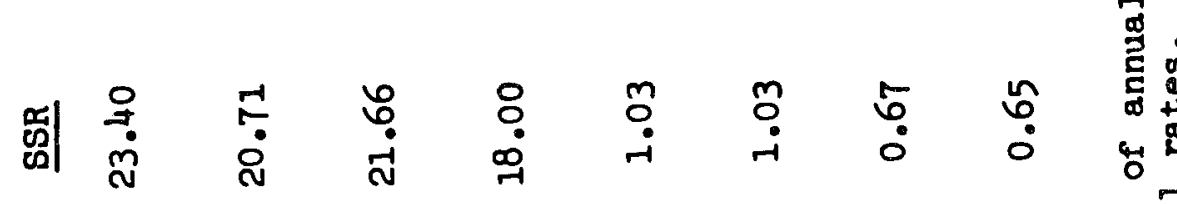
- ․ํ

$\stackrel{0}{+\infty}$ 空

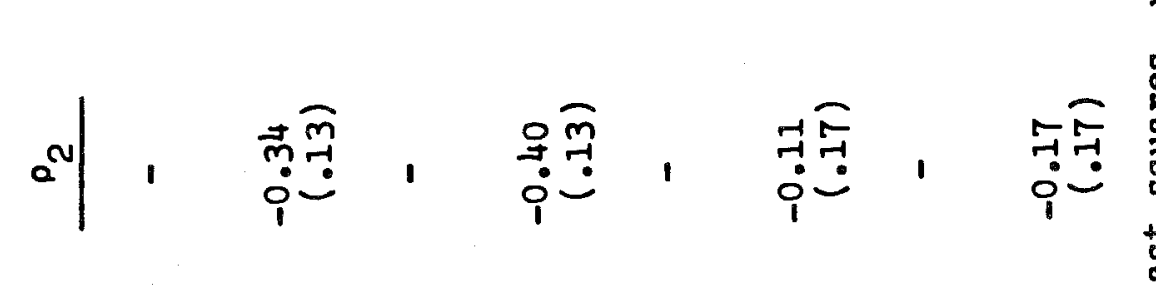

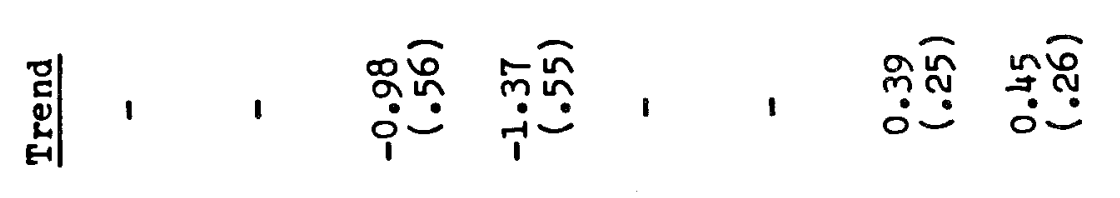
\&

苗 동

这

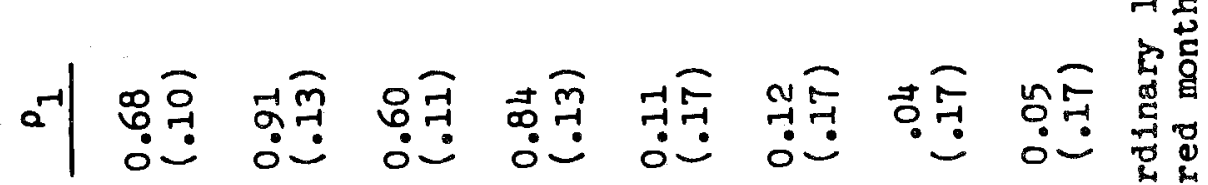
क Ш 言

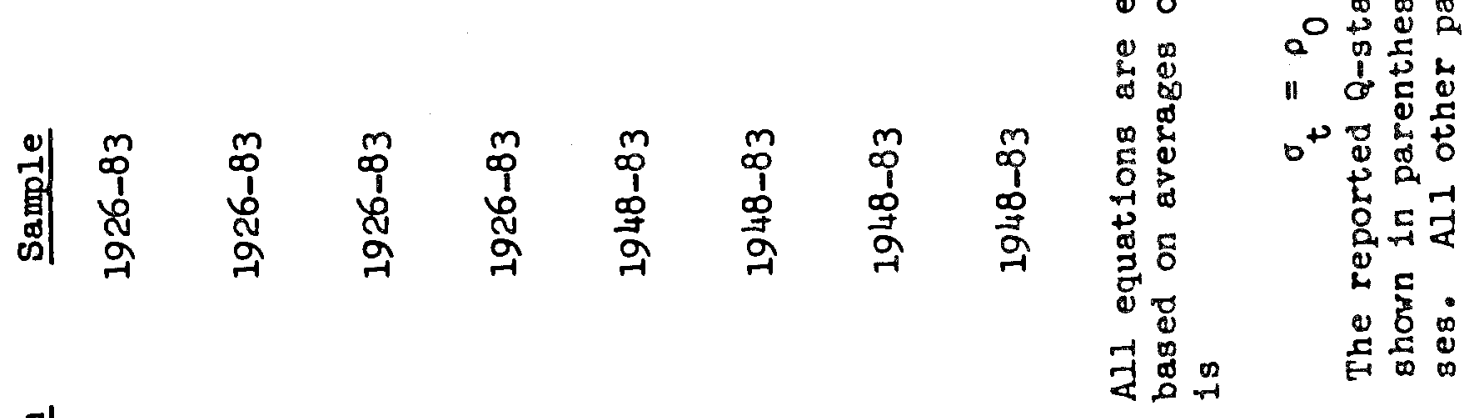

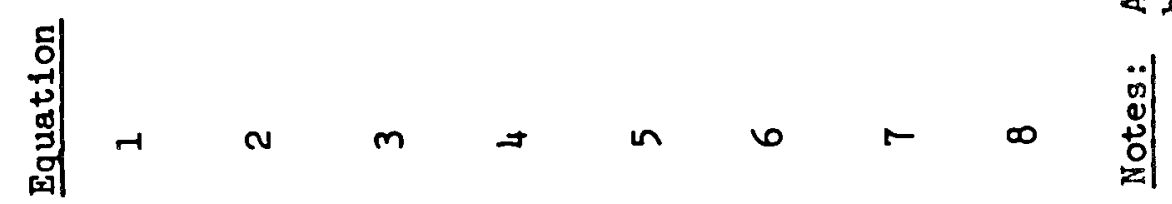


size of these tests may be substantially different from their nominal size. Dickey and Fuller (1981) present tables of adjusted critical t-values for various sample sizes to test the bypothesis of a unit root. The last column in Table 2 shows that t-statistic against the hypothesis $\rho_{1}=1$ along with the appropriate critical t-value for the $95 \%$ confidence interval. 7 In each case we are able to reject the null hypothesis of a unit root.

Our analysis so far has assumed that market volat1lity can be modelled as a stationary time series. Some research, however, has suggested that volatility may trend over time. If so, this would imply that our estimated autocorrelations are biased upwards. The equations in rows $3,4,7$, and 8 of Table 2 present simple tests for the existence of trends over various sample periods. They suggest a positive trend for the time period 1948-1983, and a negative trend for 1926-1983. However, the findings also show that the null hypothesis of no trend cannot be rejected in the 1948-1983 period cannot be rejected.

These results contradict Pindyck's (1984) claim that there has been a clear upward trend in market volatility over the last thirty years. He pre-smooths monthly volatility estimates by computing twelve-month moving averages before looking for trends, and this makes his conclusions difficult to evaluate. Even if there were trends, however, it is important to recognize that only unexpected deviations from trend should affect asset returns. If the trend rate of volatility growth rises abruptly, that should lead to a one-time adjustment in share prices, but it cannot account for a low rate of return over an extended period.

\subsection{Volatility Estimates Based on Daily Data}

Our second volatility estimator was based on daily data; it follows closely on Merton's (1980) estimator.8 Using daily returns on the Staridard and Poor's 
500 Stock Index, we computed

$$
\hat{\sigma}_{t}^{2}=\sum_{1=1}^{21} \tilde{B}_{1 t}^{2} / 21
$$

where st $_{\text {it }}$ is the daily return adjusted for non-trading days. In daily data, measuring the returns around the risk-free rate would have virtually no effect on the estimated volatilities. The twenty-one trading day intervals which we use correspond roughly to months of calendar time.

The autocorrelogram and partial autocorrelogram for this volatility estimator are shown in Table 3. In this case, the data clearly exhibit positive serial correlation. Again, the persistence of volatility is relatively unimportant from an economic perspective. The first order autocorrelation coefficient obtained using monthly data is .596 , which is equivalent to an autocorrelation coefficient of only (.596)12, or .002, in annual data. This is not inconsistent with the estimates obtained using the post-war monthly volatility data in the last section, since we could not reject the null hypothesis that there was no serial correlation in volatility.

Table 4 shows estimated autoregressive models for the volatility series calculated from daily data. Once again, the first or second order autoregressive process provides an adequate description of the data. The hypothesis that the coefficients on all variables lagged more than two periods equalled zero could never be rejected. Higher lagged terms have small, as well as statisticaliy insignificant, coefficients. None of the estimates of $P_{3}$ or ph ever exceeded .10 in absolute value. The tests against the null hypothesis of $p_{1}=1$ again clearly reject the hypothesis that volatility follows a random walk. The half life for a shock in the $A R(1)$ model is less than three months. 
Table 3: Autocorrelation in Monthly Stock Market Volatility

Lag Length (Months)

$\begin{array}{lrl}1 & 0.596(.071) \\ 2 & 0.446(.071) \\ 3 & 0.330(.071) \\ 4 & 0.225(.071) \\ 5 & 0.198(.071) \\ 6 & 0.186(.071) \\ 7 & 0.169(.071) \\ 8 & 0.154(.071) \\ 9 & 0.172(.071) \\ 10 & 0.192(.071) \\ 11 & 0.168(.071) \\ 12 & 0.050(.071) \\ 13 & 0.021(.072) \\ 14 & 0.009(.071) \\ 15 & 0.021(.071) \\ 16 & -0.003(.075) \\ 17 & 0.013(.069) \\ 18 & -0.036(.070) \\ 19 & -0.097(.071) \\ 20 & -0.113(.071) \\ 21 & -0.107(.071) \\ 22 & -0.115(.071) \\ 23 & -0.085(.071) \\ 24 & -0.062(.071)\end{array}$

Partial

Autocorrelation

Autocorrelation

$0.596(.071)$
$0.142(.071)$
$0.027(.072)$
$-0.025(.072)$
$0.059(.071)$
$0.056(.072)$
$0.024(.071)$
$0.016(.072)$
$0.067(.071)$
$0.069(.071)$
$-0.009(.074)$
$-0.161(.071)$
$-0.009(.069)$
$0.023(.070)$
$0.034(.072)$
$-0.063(.071)$
$0.020(.073)$
$-0.070(.071)$
$-0.097(.072)$
$-0.047(.071)$
$0.017(.072)$
$-0.003(.070)$
$0.045(.072)$
$0.002(.091)$

Source: The table shows the estimated autocorrelogram for monthly estimates of market volatility. Each month's estimate is based on the average of squared daily returns on the S\&P 500 Index for the period 1968:001 to 1984:180. A total of 197 monthly observations, based on 4137 daily observations, are used. Standard errors are shown in parentheses. 


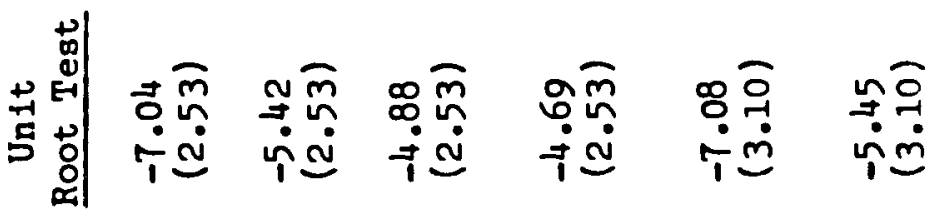

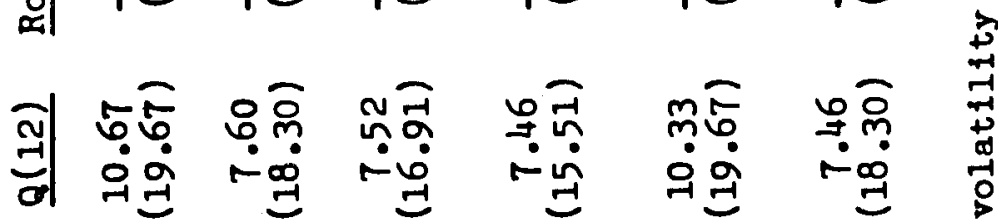

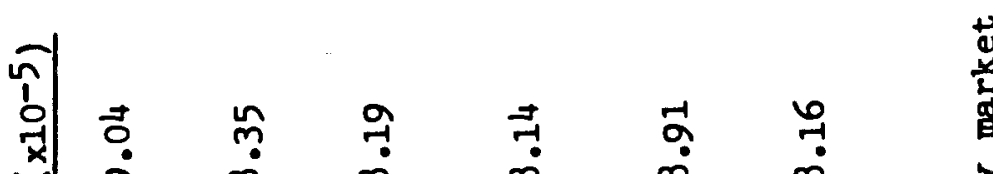

$\underset{\substack{1 \\-1}}{\stackrel{d}{1}}$

$\stackrel{d}{\underset{\omega}{\infty}}$

品|

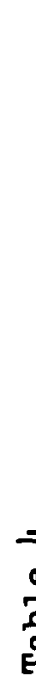

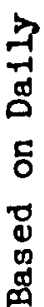

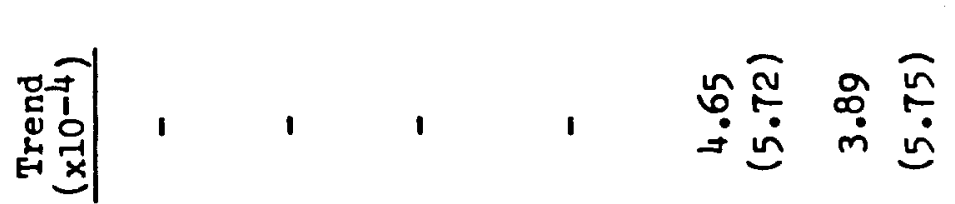

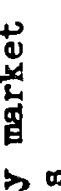

담

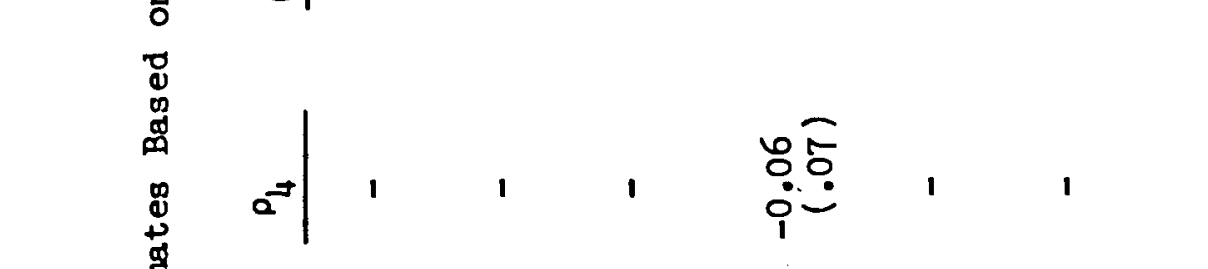

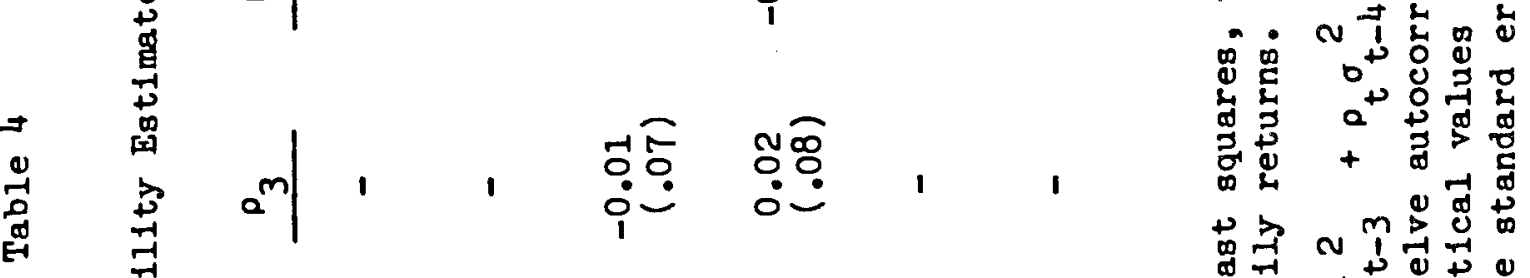

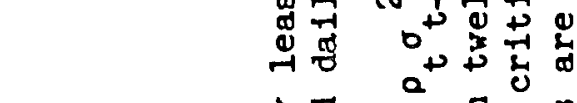

क्ष $0^{N}$ I

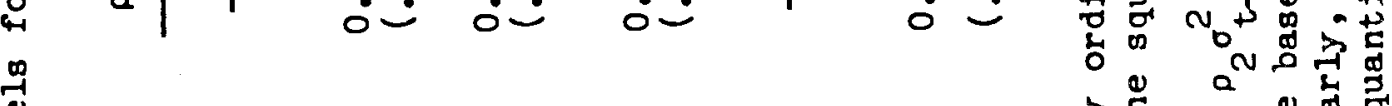

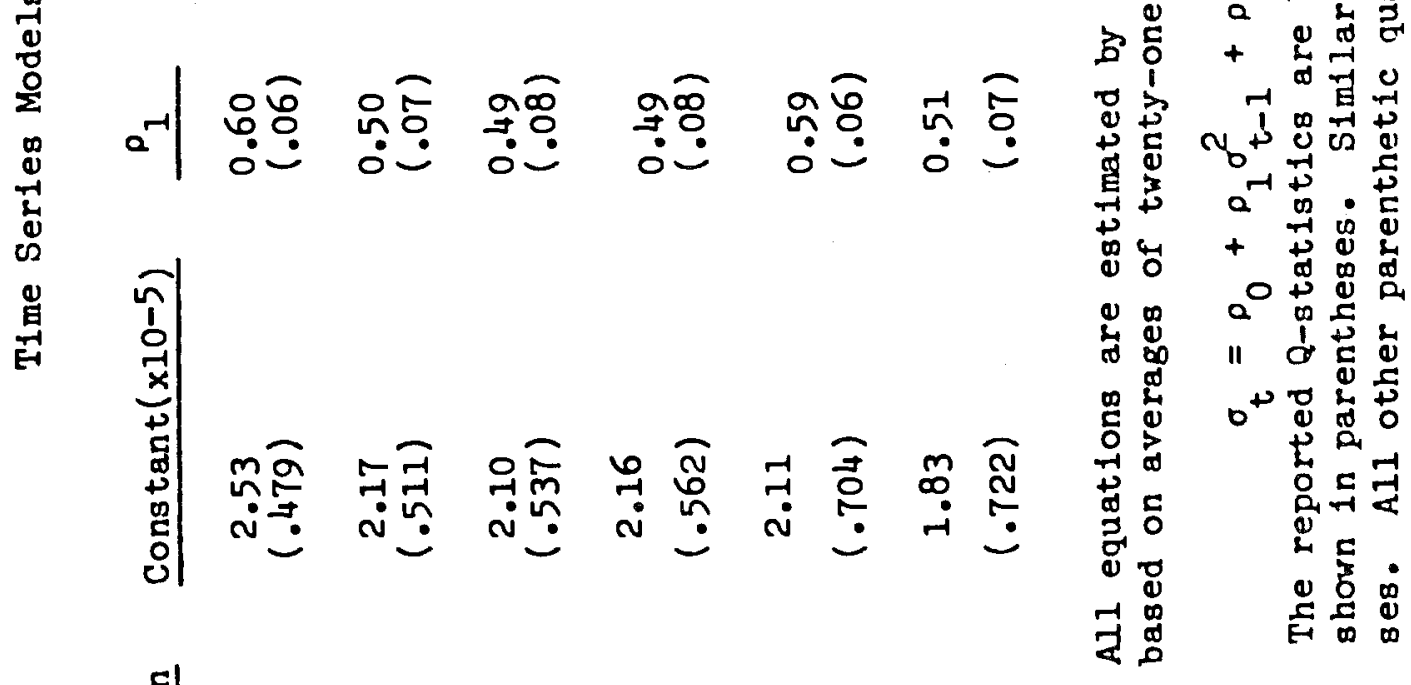

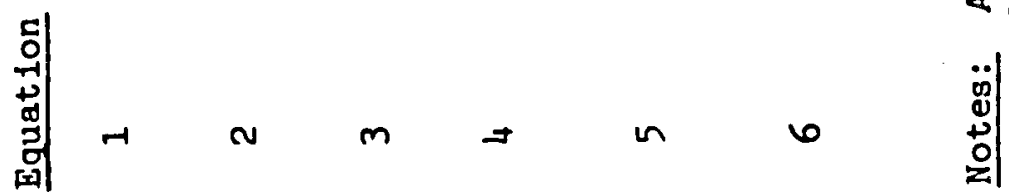


Substantive economic conclusions about the importance of volatility shocks are unaffected by the cholces between the different autoregressive models. All of our results suggest very little persistence. 9 Moreover, the results again question the importance of trends in volatility. None of the estimated time trend coefficients is statistically significant. In both the AR(1) and $A R(2)$ cases, the estimate trend coefficients have t-statistics of less than unity and the addition of trend variables has little effect on the other coefficients in these equations. 


\section{Market Volat1lities Implied by Option Premia}

The estimates presented in the last section suggest that volatility shocks are short-lived. "However, the estimated serial correlation parameters might be blased downward by measurement error, and they may also fall to reflect market particlpants' bellefs about volatility persistence. To address these problems, we analyzed the persistence in volatilities inferred from option premia. Unfortunately, options on stock market indices such as the S\&P 500 have been traded for too short a period to make analyzing them informative. However, the Chicago Board Options Exchange ( $\mathrm{CBOE}$ ) has computed an index of the price of a standardized stock option on every Thursday since January 8, 1976.10

...the CBOE Call Option Index is an average of percent option premiums; for each CBOE underlying stock, a market premium is estimated for a hypothetical six-month, at the money option using the market premiums of existing option series. This estimated market premium is expressed as a percentage of the stock price. The CBOE Call Option Index for a given day is the arithmetic average of all such percent premiums on CBOE underlying stocks on that day.[CBOE(1979), p. 1]

These data are now available for a period of eight and one half years and it is possible to analyze the persistence of volatility expectations using them.

The CBOE Index does not correspond to the option premium of any traded security. It is a measure of this option premium on the "representative share" for which options are traded on the CBOE. As such, the implied volatility should be substantially higher than the volatility of the market, since the market is a weighted average of many imperfectly correlated shares. While our estimates of the implied volatility on a representative share are not directly comparable to the volatilities estimated in the last section, our assumption is that their serial correlation properties should be reasonably similar.11 
To estimate the volatility of the "representative stock" implied by the $C B O E$ index, we assumed that the dividend yield on this share equalled that on the S\&P 500.12 We followed Black's (1976) suggestion for dividend adjustment and subtracted the present value of dividend payments over the life of the option from the price of the stock. We assumed that the option on the representative stock was priced accordimg to the Black-Scholes (1973) formala, and applied a numerical search algorithm to determine the variance of returns which was consistent with the observed option price, risk free rate, and market dividend yield. The CBOE Index is standardized to apply to an option on a stock with a current price of $\$ 40.00$, and since the index applies to at the money opt1ons, the strike price is $\$ 40.00$ as well. The weekly data on the CBOE Index, as well as our estimates of the implied volatilities, are shown in the Data Appendix.

The movements our implied volatilities were compared with those of sixmonth ex post volatilities estimated from daily returns on the S\&P 500; the two series cohere reasonably well. Figure 1 shows the movments in these two series, each divided by its mean, for the 1976-1984 period. A positive association between the series is readily apparent. Both series rise throughout the late 1970s, and decline during the 1982-1984 period. The CBOE implied volatility does not rise as dramatically as the ex poste volatility series during the 1981 stock market rally, although it does increase.

Table 5 shows the estimated autocorrelogram and partial autocorrelogram for the implied volatility series. These are weekly data, and so the estimated autocorrelations are higher than those in the earlier sections. The first order autocorrelation, for example, is .971 . However, these results confirm the 


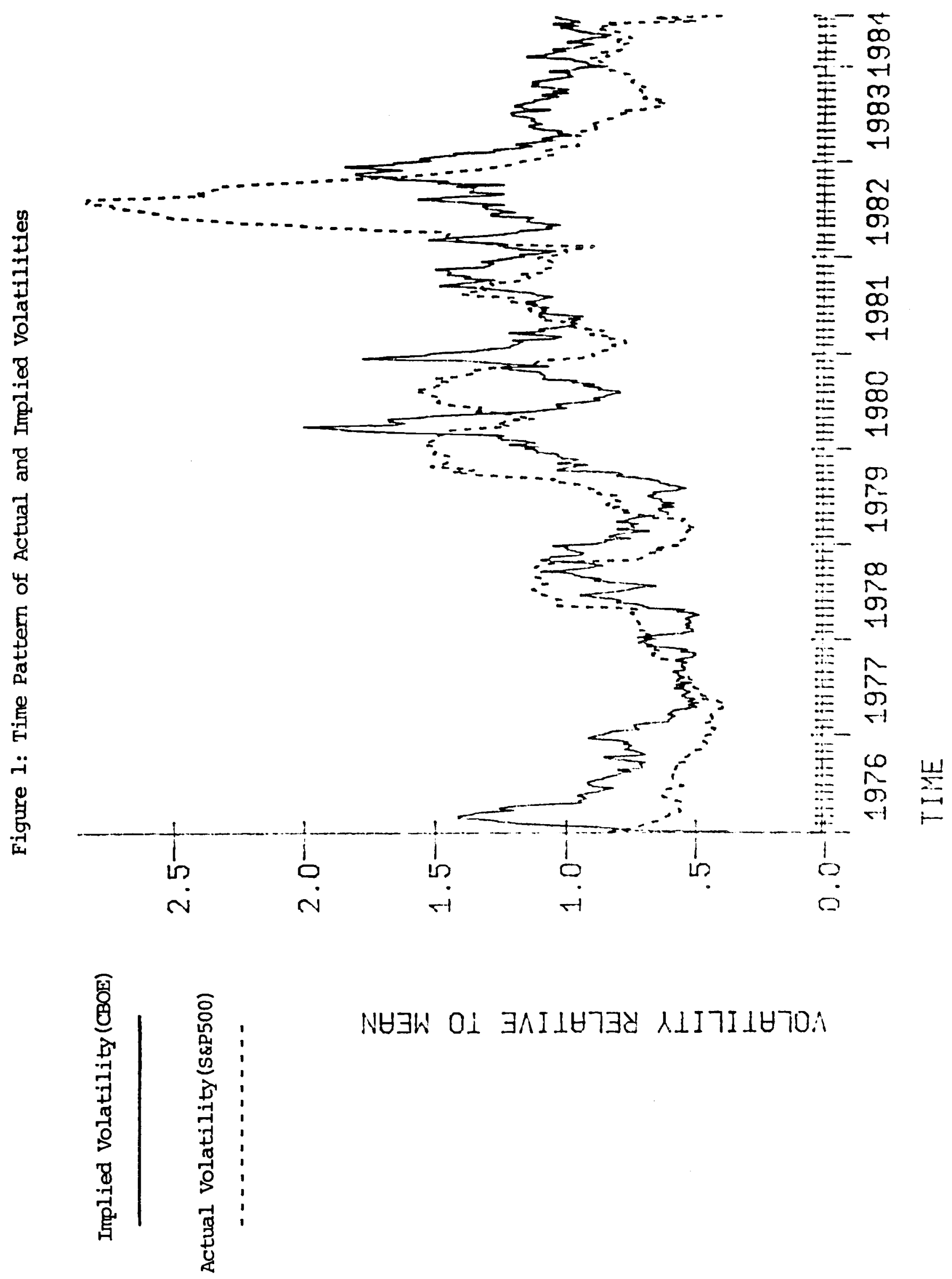


Table 5: Autocorrelation In Volatility Forecasts Implied by Option Premia

Lag Length
(weeks)

(weeks)

1

2

3

4

5

6

7

8

9

10

11

12

13

14

15

16

17

18

19

20

21

22

23

24

25

26

\section{Autocorrelation}

$0.971(.047)$

$0.939(.082)$

$0.903(.106)$

$0.869(.125)$

$0.835(.142)$

$0.802(.157)$

0.767 (.171)

$0.734(.184)$

$0.703(.195)$

$0.673(.195)$

$0.650(.195)$

$0.629(.195)$

$0.612(.195)$

$0.589(.195)$

$0.566(.195)$

$0.545(.195)$

$0.525(.195)$

$0.507(.195)$

$0.493(.195)$

$0.482(.195)$

$0.473(.195)$

$0.466(.195)$

0.458 (.195)

$0.450(.195)$

$0.443(.195)$

$0.439(.195)$
Partial

Autocorrelation

$0.971(.047)$

$-0.056(.047)$

$-0.087(.047)$

$0.029(.047)$

$-0.028(.047)$

$-0.003(.048)$

$-0.043(.047)$

$-0.003(.043)$

$0.032(.047)$

$-0.003(.056)$

$0.092(.047)$

$-0.002(.044)$

$0.062(.047)$

$-0.130(.047)$

$-0.026(.047)$

$0.064(.047)$

$-0.014(.046)$

$0.012(.046)$

$0.059(.047)$

$0.053(.047)$

$0.025(.047)$

$0.028(.048)$

$-0.032(.047)$

$-0.008(.048)$

$0.004(.046)$

$0.027(.048)$

Source: Estimates of volatility forecasts were determined by inverting the Black-Scholes option valuation formula to obtain the volatility implied by $C B O E$ option premia indices. These data were avallable for the period 1976:1 to 1984:26, for a total of 447 weekly observations. See appendix for further details and data description. Standard errors are shown in parentheses. 
earlier conclusions that volatility changes are not persistent. One year after a shock to volatility, expected volatility w1ll exceed its mean by only (.971)52 $=.22$, or twenty two percent, of the initial shock. The partial autocorrelogram. again suggests that a first order autoregressive representation is appropriate for this series. The statistical insignificance of partial autocorrelations at lags of more than one week is indicative of an $\operatorname{AR}(1)$ structure in these data. Table 6 reports estimates of several time series molels for these data. Equations for our entire data period, comprising 447 weeks, are reported in the first four rows of the table. The hypothesis that the residuals from the $\mathrm{AR}(1)$ model are white noise is nearly rejected at standard levels, as shown by the reported $Q-s t a t i s t i c s . ~ T h e ~ A R(2)$ results do not suffer from this difficulty. The higher order (third and fourth order) autocorrelation parameters are never statistically significant. The implied responses to a volatility shock are similar in all of the estimated models. They suggest that the half life for a volatility shock is about six months.13 Although the estimated weekly autocorrelation is near unity, the last column of the table shows that the hypothesis of a unit root is still rejected in each case.

Because each weekly observation on the $\mathrm{CBOE}$ Index depends on forecasts of volatility for each of the next twenty six weeks, two consecutive observations on the implied volatility will have twenty five weeks of forecast volatilities in common. This may bias our estimated autocorrelations. We therefore estimated autoregressive models using non-overlapping data periods, corresponding to every twenty-sixth observation in our data set. The estimated $A R(1)$ and $A R(2)$ models are reported in the last two rows of the table. The estimated six-month 


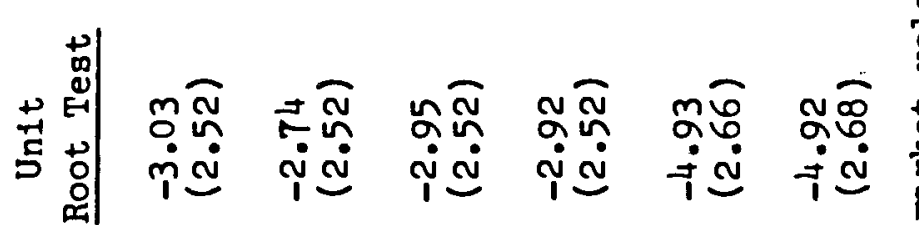

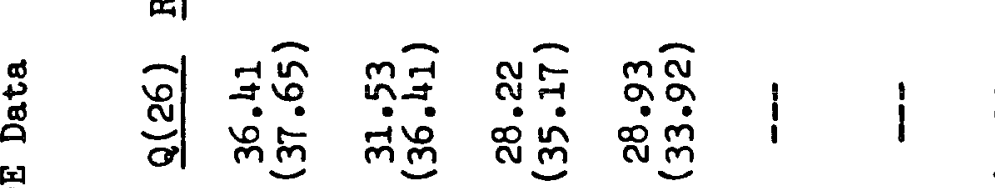

畟

ธ

:

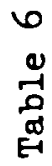

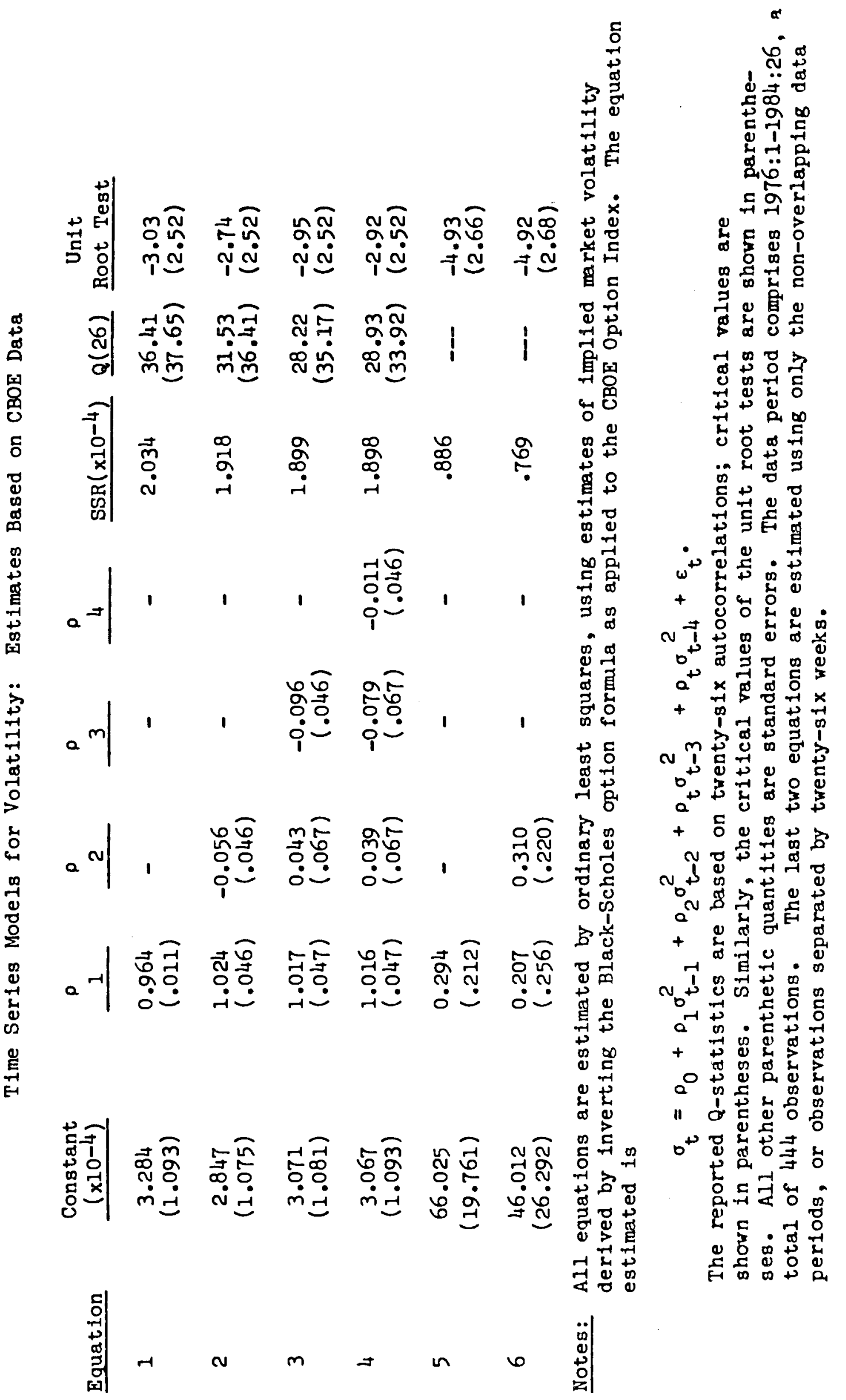


autocorrelation coefficient from these data is .43 , which is only slightly lower than the six-month autocorrelation implied by our weekly estimates. The results again suggest that over half of a volatility shock vanishes within six months. 


\section{The Term Structure of Implied Volatilities}

The CBOE Call Option Index data provide strong support for the transient character of volatility shocks. However, they do not permit us to directly. Investigate how long-term expectations of volatility respond to changing shortterm volatility expectations. A second source of option data can illuminate this issue. Since 1979, Valueline has computed indices of option premia at three and $81 x$ month maturities. We inverted these option premia indices using the same procedure which we applied to the CBOE data.14

The availability of two different maturity option indices provides an opportunity for additional tests of the persistence hypothesis. The implied volatility for the six month options was assumed to equal the average of the expected three month volatilities for the next three months as well as the three months following them:

$$
t, 6^{\sigma_{t}^{2}}=\left(t, 3 \sigma_{t}^{2}+t, 3^{\sigma_{t+13}^{2}}\right) / 2
$$

In this notation, $s, \sigma_{t}^{2}$ is the volatility expected to prevail, as of time $t$, over the $k$ months beginning in week $s$. The assumption in (18) allows us to solve for an estimate of the implied forward volatility which is expected to prevail for the three month period beginning three months from the current week:

$$
t+13,3^{\sigma^{2}}=2 t, 6^{\sigma_{t}^{2}}-t, 3^{\wedge} \hat{\sigma}_{t}^{2}
$$

We can use the estimated forward volatilities to study the change in the implied forward volatility which occurs when the current three-month "spot" Implied volatility changes. The results of this estimation are shown below: 


$$
t+13,3_{t}^{\sigma_{t}^{2}}-{ }_{t+12,3} \hat{\sigma}_{t-1}^{2}=\underset{(.0769)}{-.0233}+\left.\underset{(.050)}{0.511}\right|_{t, 3^{\sigma} t}{ }^{a}{ }_{t-1,3^{2}} \hat{\sigma}_{t-1}^{2} \mid
$$

These results indicate that when current volatility expectations change, expected volatility in future periods also changes. However, they also constitute further evidence for our contention that volatility shocks are not persistent. One year after a volatility shock, these estimates imply that on ly seven percent of a shock will still persist. The half life of a volatility shock according to these data is just over three months. One year after a ten percent shock to volatility, the three-month forecast of volatility would only be 1.3 percent greater than in the initial period. 


\section{Conclusions and Implications}

Our findings auggest that shocks to stock market volatility are not persistent. Th1s is 1llustrated in Figure 2, which shows the impulse response functions corresponding to several of the estimated time series models for volatility. These functions, which show the moving average representation of each process, depict the evolution of volatility following a "shock" equal to ten percent of the steady-state value of volatility. While the speed with which the shock dissipates varies across models, the half iffe of the shock never exceeds two years. For the equations corresponding to the CBOE and daily volatility estimators, the half-life of a volatility shock is less than half a year.

Our empirical results suggest that changes in volatility should affect expected required returns for periods not substantially greater than two years. This means that they can only have a very limfted impact on the level of share prices. A doubling of volatility would reduce the level of the market by only about nine percent.15 Since actual volatility fluctuations are usually smaller than this, we doubt that changing volatility accounts for any large fraction of market fluctuations. This observation applies both to the problem of explaining recent events and to the deeper problem of explaining the sources of stock price fluctuations.

Our work deepens the puzzle of explaining the strong negative correlation, observed by Black (1976) and Schmalensee and Trippi (1978), between stock market returns and volatility. Black (1976) showed that the inverse correlation between volatility and returns was so strong that a positive one percent return on a stock implied more than a one percent reduction in volatility; this 


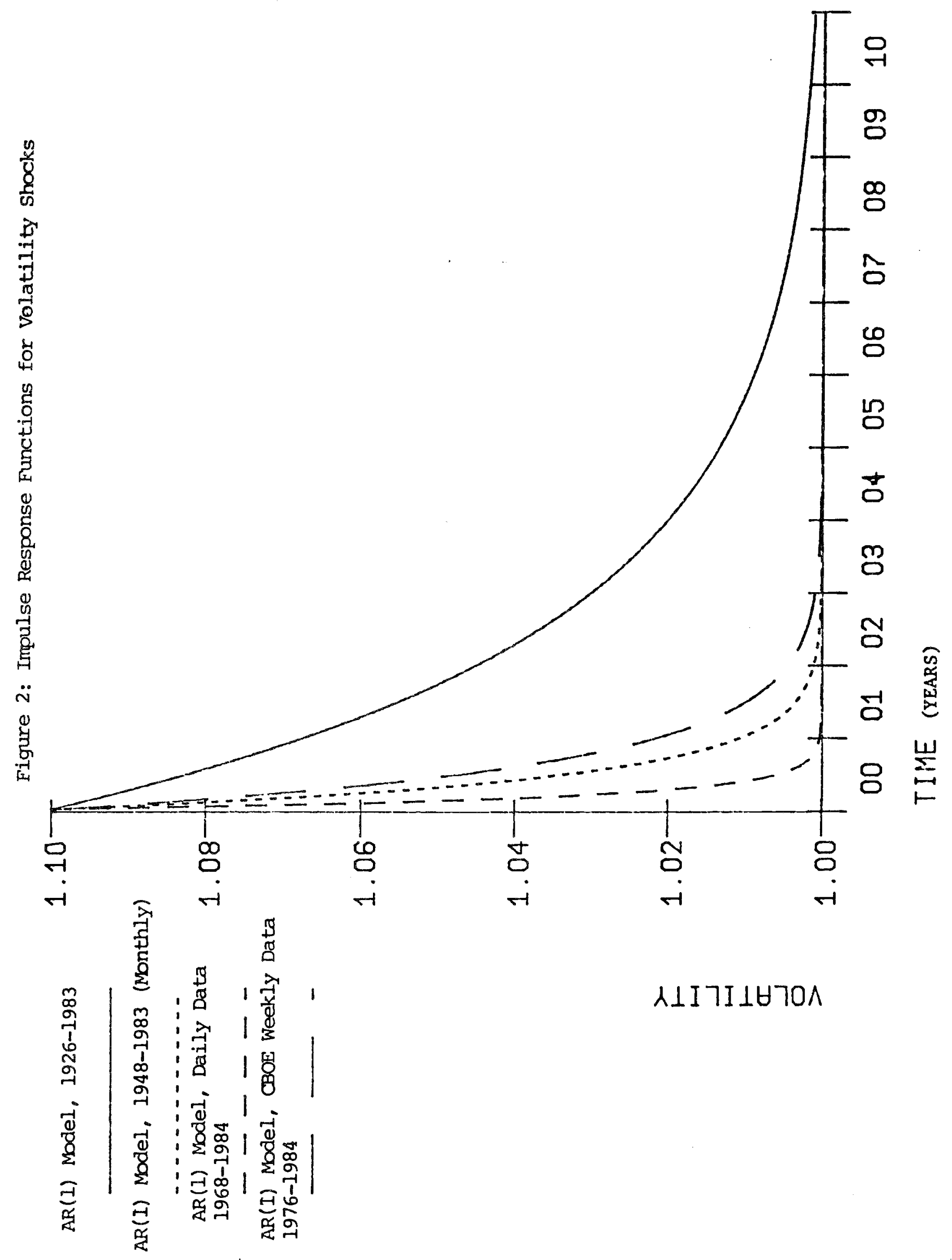


implies that ralsing the share price actually reduces the dollar volatility of the stock. The finding that volatility is not highly persistent suggests that autonomous changes in volatility should have only a relatively small effect on share prices. If Black's (1976) "leverage effect" explanation of the relationship between returns and volatility were correct, then one would expect to observe that volatility, like prices, would follow a random walk.

One possible explanation for the observed data is that the same events which make the returns to capital more uncertain also reduce their expected value. This coincidence in the arrival of stochastic shocks would lead to an apparent relationship between volatility changes and share prices, although in fact no such causal link exists. Another possibility is that when adversity strikes, firms are expected to respond with new strategies. Between the time the market anticipates that some new policy will be chosen and the time this policy is actually announced, uncertainty and therefore volatility may increase. 


\section{Endnotes}

1. These data are based on Ibbotson (1984).

2. To the extent that there is measurement error in our estimates of volat1lity, the estimated serial correlation coefficients may be biased dowmard. In the next section we use estimates of volatility expectations which are less susceptible to these difficulties.

3. Merton (1980) observes that although estimators of the variance which center the estimated returns around a point which is not their sample mean will be biased, these biases are trivial. He estimates variances using uncentered returns; Pindyck (1984) estimates variances for twelve month periods by computing second moments centered around the overall mean return in his sample.

4. We used Box-Jenkins (1970) Q-statistics to test the null hypothesis of no serial correlation of up to fifth order. The values of the test statistics were 32.9 for the 1926-1983 period, 4.70 for 1948-1983, and 4.47 for 1960-1983. The critical value for rejecting the null hypothesis of at the .05 level is 12.59 .

5. The finding that low-order autoregressive processes provide an adequate description of the variance of market returns suggest that it may be possible to apply the econometric techniques for time-varying heteroscedasticity, suggested by Engle(1982), when studying the behavior of security returns.

6. The same conclusion emerged when we examined changes in volatility. This is shown by the following equation, estimated for the 1948-1983 period:

$$
\hat{\sigma}_{t}^{2}-\hat{\sigma}_{t-1}^{2}=\underset{(3079.1)}{1083.3}-(.438)\left[\hat{\sigma}_{t-1}^{2}-\hat{\sigma}_{t-2}^{2}\right]
$$

The coefficient on the lagged volatility change is negative and has a t-value of 2.83, clearly different from zero.

7. Critical values of the unit root tests are drawn from Dickey and Fuller (1981), Tables I and II.

8. Merton (1980, Appendix A) discusses two adjustments to estimated volatility series. The first, for nontrading days, is implemented in our study. The second, which corrects for nontrading shares in the stock index, multiplies the estimated volatility by a constant. Since our study is concerned with the autocovariance and not the level of the volatility series, and the former is unarfected by multiplication by a constant, we did not make the correction.

9. The results of estimating a model in changes were:

$$
\hat{\sigma}_{t}^{2}-\hat{\sigma}_{t-1}^{2}=\frac{1.44 \times 10^{-7}}{\left(3.42 \times 10^{-6}\right)}(.068) \cdot\left[\hat{\sigma}_{t-1}^{2}-\hat{\sigma}_{t-2}^{2}\right\rfloor .
$$

Again, this suggests negative serial correlation.

10. A further description of this series may be found in $\operatorname{CBOC}(1979)$. 
11. Latané and Rendelman (1976) computed implied standard deviations for a series of options over a thirty nine week period and discovered that these implied standard deviations tended to move together. Schmalensee and Trippi (1978) found similar results. These coincident movements in volatility are the market-wide volatility shifts we hope to capture.

12. We assumed that dividends were paid as a continuing flow at rate $\lambda$ per year, where $\lambda$ is the current yield on the S\&P 500.

13. We also considered the serial correlation of changes for the nonoverlapping differences:

$$
\hat{\sigma}_{I, t}^{2}-\hat{\sigma}_{I, t-26}^{2}=\underset{(0.00013)}{0.00012}-\underset{(.044)}{.425}\left[\hat{\sigma}_{I, t-26}^{2}-\hat{\sigma}_{I, t-52}^{2}\right]
$$

where the subscript I denotes an implied volatility.

14. The Value Line data were avallable for the period 1980:16 to 1984:26; this constitutes a total of 220 weeks. However, there were 17 weeks of missing data. This precluded calculating the long autocorrelograms which are reported for the other volatility series. However, the first order autocorrelations for these series, .88 for the three month implied volatility and .87 for the six month, were roughly consistent with earlier findings.

15. This calculation is based on $\rho_{1}=.21$, the estimate from the $\mathrm{CBOE}$ implied volatilities, and the other parameter values described in Section 1. 


\section{$\underline{\text { References }}$}

Black, Fischer, 1975, Fact and fantasy in the use of options, Financial Analysts Journal $31,36-41,61-72$.

Black, Fischer, 1976, Studies of stock price volat1lity changes, Proceedings of the 1976 Meetings of the American Statistical Association, Business and Economic Statistics Section, 177-181.

Black, Fischer and Mron Scholes, 1973, The pricing of options and corporate liabilities, Journal of Political Economy 81, 637-659.

Box, G.E.P. and G. Jenkins, 1970, Time Series Analysis: Forecasting and Control (Holden Day: San Francisco).

Chicago Board Options Exchange, 1979, The CBOE call option Index: Methodology and technical considerations (Research Department of the CBOE, Chicago,IL).

Dickey, David A. and Wayne A. Fuller, 1981, Likelihood ratio statistics for autoregressive time series with a unit root, Econometrica 49, 1057-1072.

Engle, Robert F., 1982, Autoregressive conditional heteroscedasticity with estimates of the variance of United Kingdom inflations, Econometrica 50 , 987-1008.

Ibbotson, Roger G., 1984, Stocks, bonds, bills, and inflation: 1984 yearbook, (R.G. Ibbotson Associates, Chicago, IL).

Latane, H. and R. Rendleman, 1976, Standard deviations of stock price ratios implied in option prices, Journal of Finance $31,369-381$.

Malkiel, Burton G., 1979, The capital formation problem in the United States, Journal of Finance $34,291-306$.

Merton, Robert C., 1973, An intertemporal capital asset pricing model, Econometrica $41,867-887$.

Merton, Robert C., 1980, On estimating the expected return on the market, Journal of Financial Economics 8, 323-361.

Pindyck, Robert S., 1984, Risk, inflation, and the stock market, American Economic Review 74, 335-351.

Roll, Richard, 1977, An analytical valuation formula for unprotected American call options on stocks with known dividends, Journal of Financial Economics 5, 251-258.

Schmalensee, Richard and R. Trippi, 1978, Common stock volat1lity expectations implied by option premia, Journal of Finance 33, 129-47. 
$-31-$

Appendix Table A-1: Values of CBOE Index and Implied Volatilities

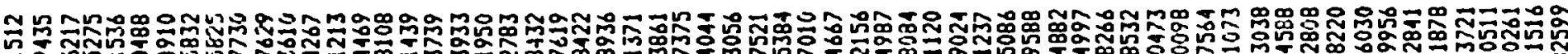

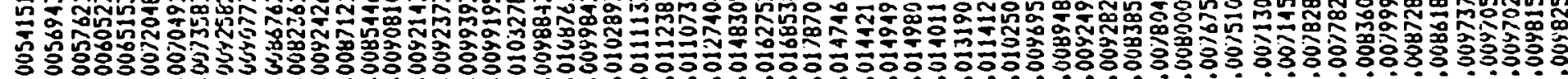

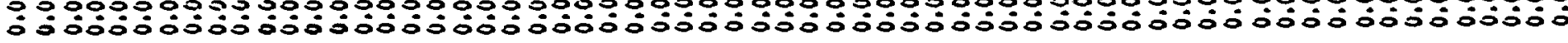

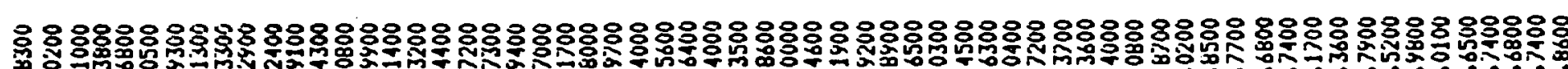

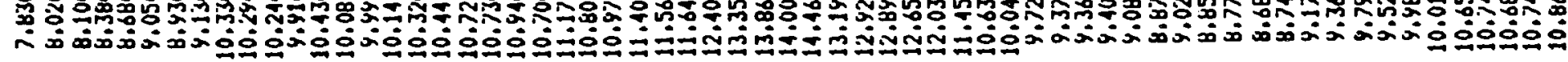

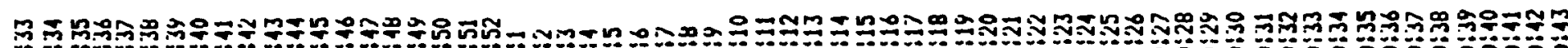

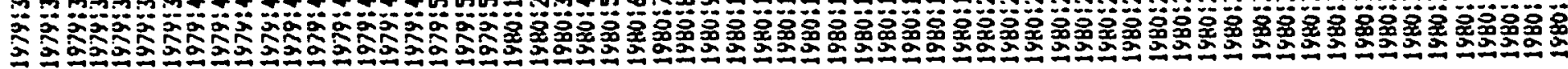

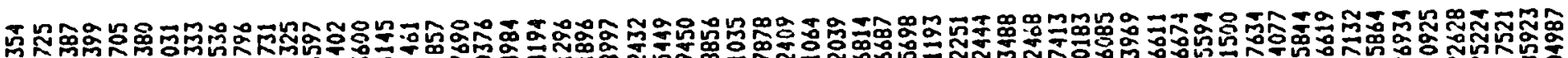

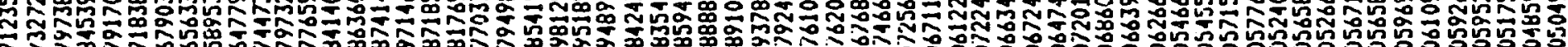

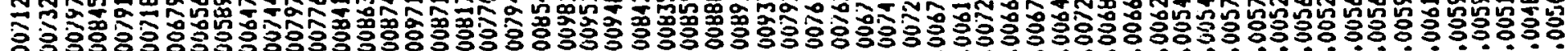

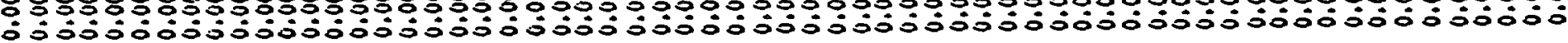

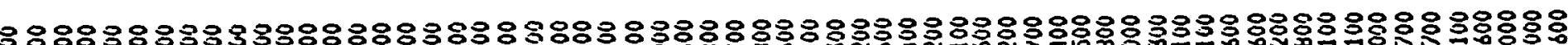

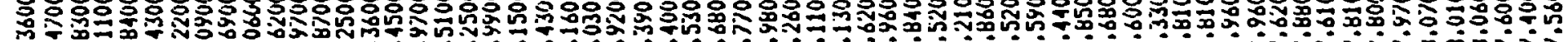

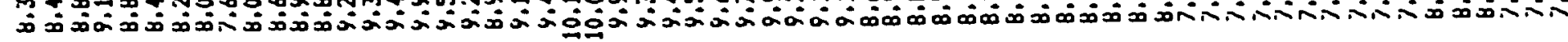

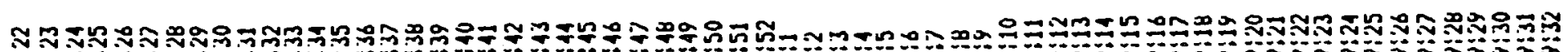

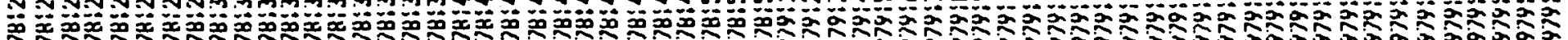

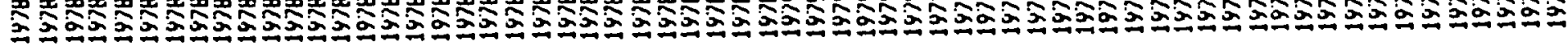

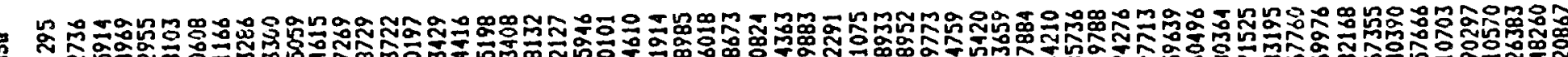

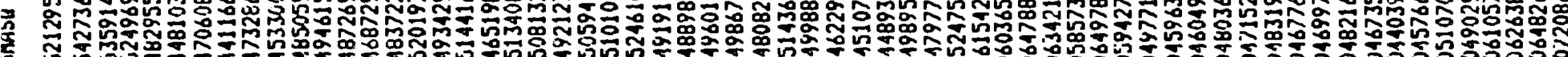

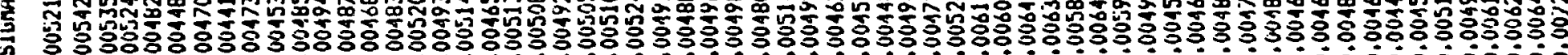

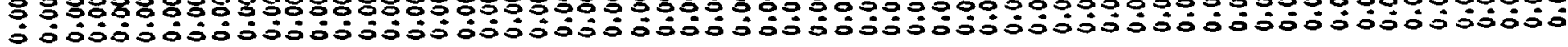

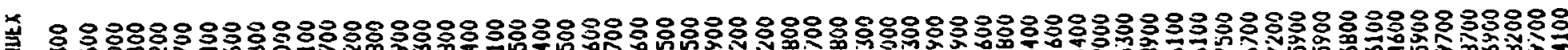

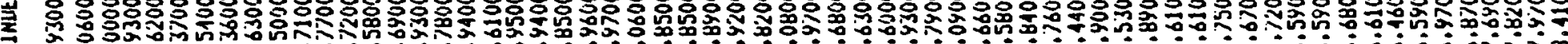
势

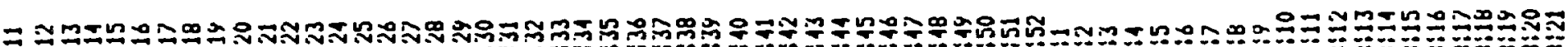

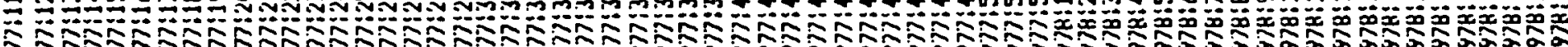

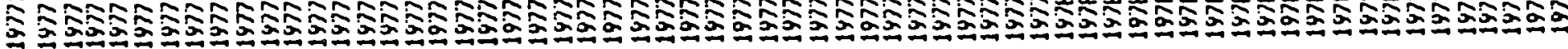

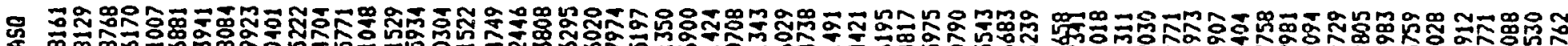

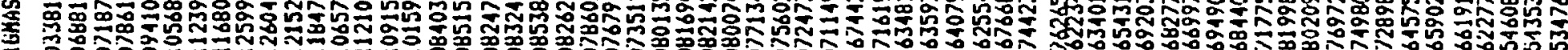

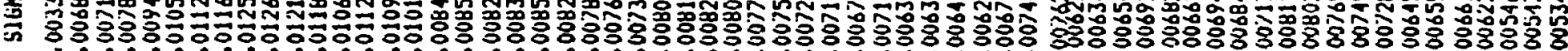

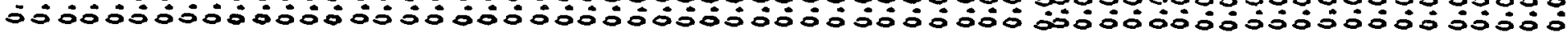

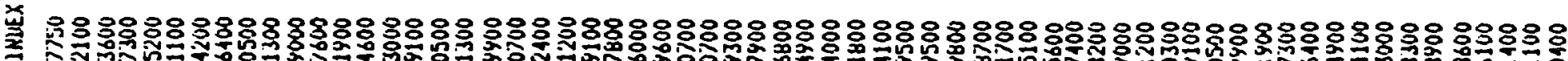

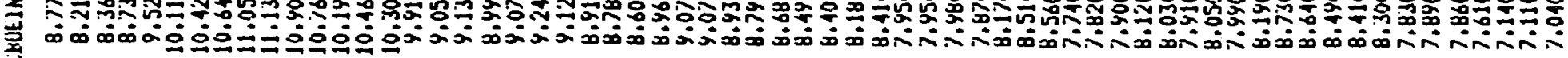

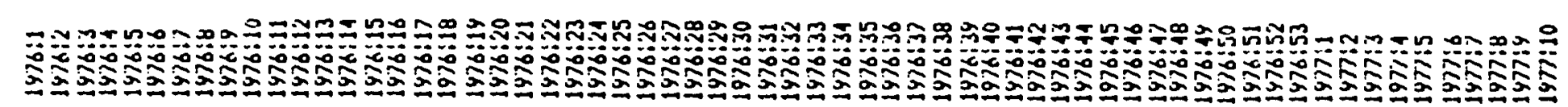




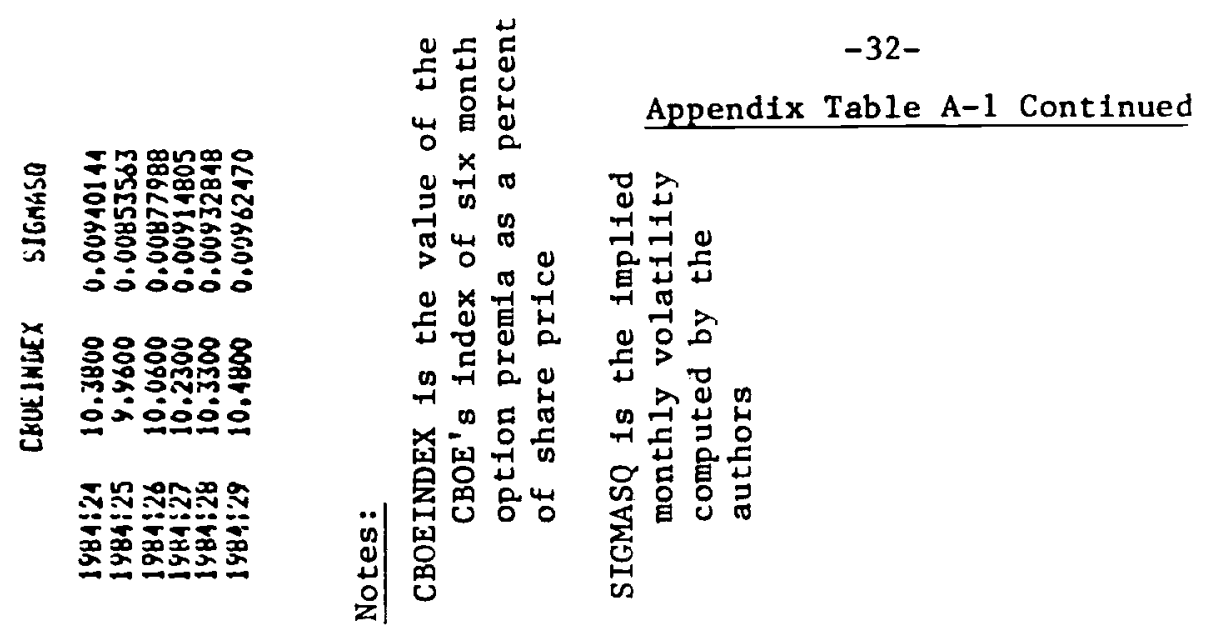

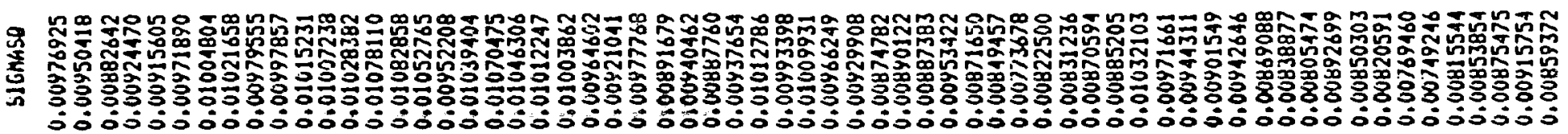

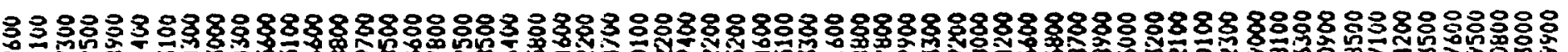

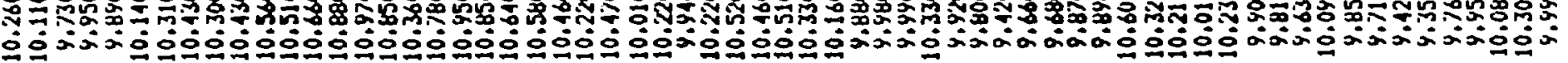

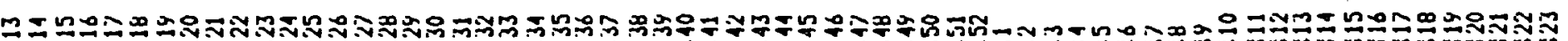

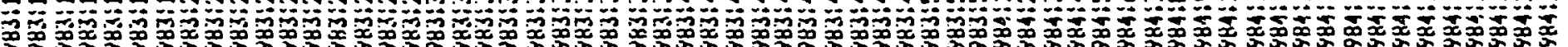

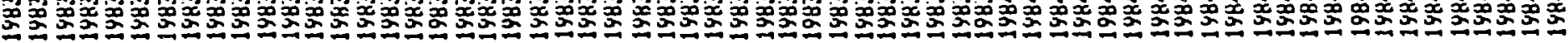

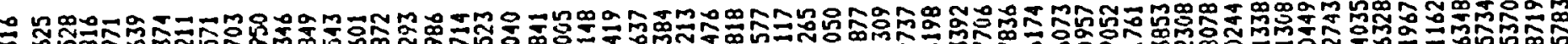

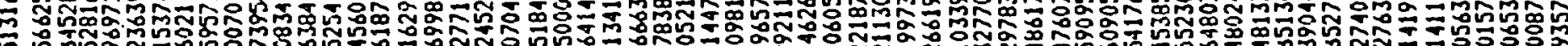

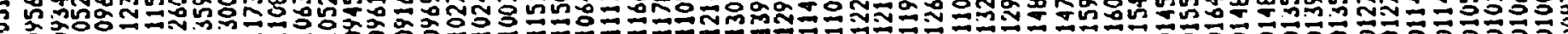

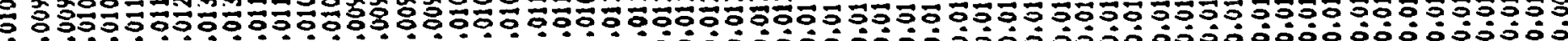

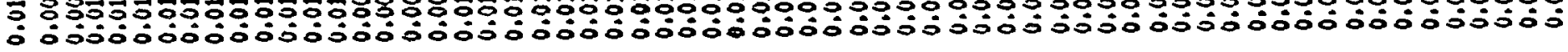

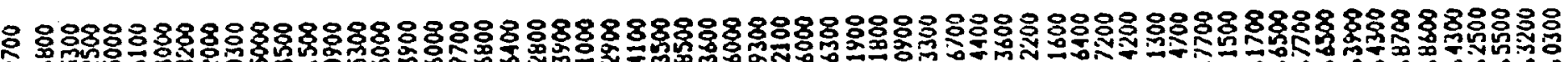

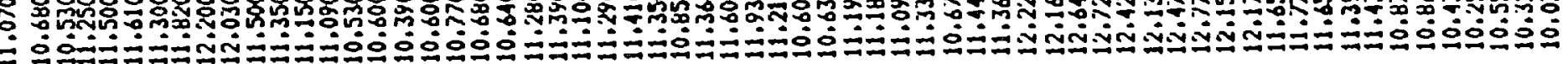

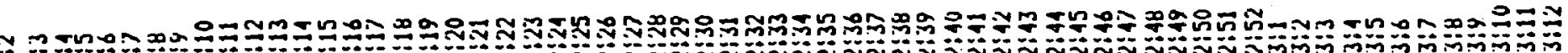

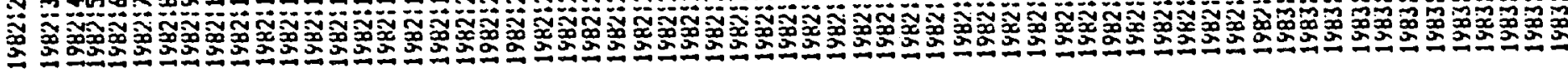

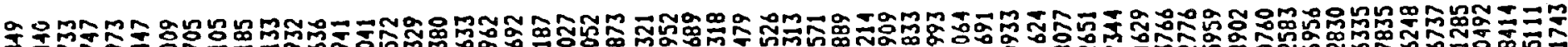

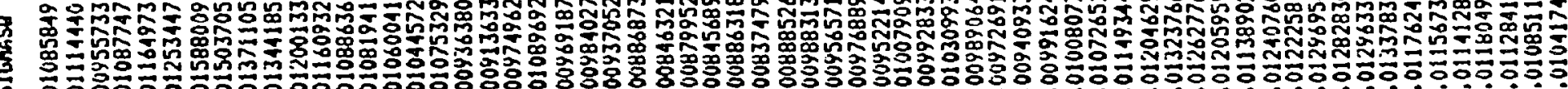

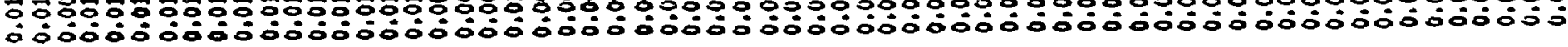

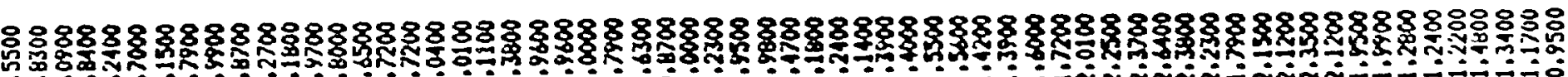

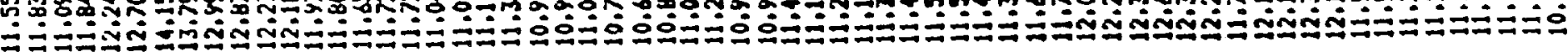

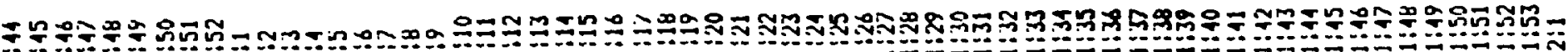

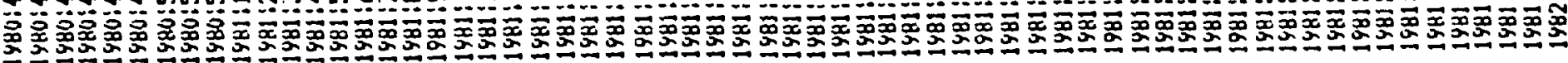

